\title{
A dádiva no turismo comunitário: constituição de vínculos sociais por colaboração solidária
}

\author{
The gift in the community tourism: establishment of social links for solidarity \\ cooperation
}

\author{
Gabriela Arantes Ferreira de Sales (SALES, G. A. F. de)* \\ Maria do Rosário Rolfsen Salles (SALLES, M. do R. R.)
}

\begin{abstract}
RESUMO - A proposta do presente trabalho é apresentar uma reflexão sobre a constituição de vínculos sociais estabelecidos a partir de um sistema de cooperação integrado, representado pelo trabalho comunitário em comunidades turísticas. O estudo foi desenvolvido tendo como referência, o sistema do dom, modelo de trocas sociais, sugerido por Marcel Mauss (1974), baseado em um encadeamento de dádivas e contra-dádivas que podem se suceder infinitamente. Serão apresentados resultados da pesquisa desenvolvida junto a oito dessas comunidades localizadas na costa leste do Estado do Ceará (Brasil). Nas comunidades estudadas, os grupos são organizados em projetos de base familiar e o turismo comunitário é idealizado partindo da ética e da solidariedade para estabelecer relações comerciais e de intercâmbio entre a comunidade e visitantes. As atividades turísticas são realizadas por meio de redes colaborativas estabelecidas a partir de vínculos sociais espontâneos como proposta para uma gestão solidária.
\end{abstract}

Palavras-Chave: Turismo; Dádiva; Trabalho Comunitário; Economia Solidária; Redes de Colaboração Solidária.

\begin{abstract}
The purpose of this paper is to present a reflection about the constitution of social links established from an integrated system of cooperation, represented by the community work in tourist communities. The study was designed having as reference, the system of gift and the social exchange model, suggested by Marcel Mauss (1974), based on a gift chain and against-gifts that can happen infinitely. It will be presented results of a research developed in eight of these communities located in the east coast of Ceará State (Brazil). In the villages studied, the groups are organized in family-based projects and the community tourism is worked based on the ethics and the solidarity to establish business and exchange relations between the community and visitors. The tourism activities are conducted throughout collaborative networks established from spontaneous social links as a proposal for a solidary administration.
\end{abstract}

Key words: Tourism; Donation; Community Work; Economy; Collaboration Network for Development.

* Graduação em Turismo pela Universidade Anhembi Morumbi. Aluna do Programa de Mestrado em Hospitalidade da Universidade Anhembi Morumbi. Assistente de Responsabilidade Social da Universidade Anhembi Morumbi e Docente no curso de Hotelaria da Faculdade UNIESP - União das Instituições Educacionais do Estado de São Paulo. Endereço para correspondência: Rua: Líbero Badaró, 487 (14 andar). CEP: 01009-000 - São Paulo (SP/Brasil). E-mail: gabbrielasales@hotmail.com

\footnotetext{
** Graduação em Ciências Sociais pela Universidade Estadual Paulista Júlio de Mesquita Filho (UNESP). Mestrado em Ciências Sociais pela Universidade de São Paulo (USP). Doutorado em Ciências Sociais Sociologia pela Universidade Estadual Paulista (UNESP) e Pós-Doutoramento em Sociologia Urbana pela École des Hautes Études en Sciences Sociales e pelo Centre de Sociologie Urbaine. Docente do Programa de Mestrado em Hospitalidade da Universidade Anhembi Morumbi. Endereço para correspondência: Rua: Casa do Ator, 275 (7 andar). CEP: 04546-090 - São Paulo (SP/Brasil). E-mail: mrrsalles@uol.com.br
} 


\section{INTRODUÇÃO}

Nas sociedades modernas, o desenvolvimento do progresso técnico-científico é relacionado fortemente à dimensão econômica. Mesmo com o surgimento de campanhas em prol de políticas que destacam os aspectos social e humano, ainda assim, a produção e o mercado, não valorizam o bem estar social e a qualidade de vida. As classes trabalhadoras que pouco têm acesso aos produtos desenvolvidos pelo mercado de supérfluos são as que mais sofrem as conseqüências de um sistema individualista e voltado ao capital. A modernidade pode ser resumida como um modo de vida que impõe um padrão consumista predador da natureza e de vidas humanas em minorias privilegiadas subordinando os objetivos sociais e ignorando os valores éticos. Partindose desse princípio, surgem, nas sociedades contemporâneas, economias alternativas que buscam valorizar o saber humano e estimular a produção associada, em função do benefício coletivo. Essa nova forma de produzir está centrada na proteção ambiental e na divisão equitativa de bens entre todos os participantes do sistema.

A proposta do presente trabalho é apresentar uma reflexão, resultado de uma pesquisa de campo em oito comunidades localizadas na costa leste do estado do Ceará (Brasil), que desenvolvem o turismo comunitário, atividade que concentra a gestão turística sob controle das comunidades receptoras, enfatiza a conservação ambiental e a valorização da identidade cultural, além de contrastar com o padrão convencional do turismo de massa, cujos pacotes rígidos e impessoais obedecem a uma lógica econômica de um retorno imediato e máximo dos investimentos. O estudo é bastante instigante, na medida em que percebe-se que desenvolvimento comunitário está associado ao modo de produção e à organização do trabalho para a gestão das atividades relacionadas à recepção e à hospitalidade. Nesse sentido, o estudo busca apresentar um diálogo sobre a constituição de vínculos sociais estabelecidos espontaneamente a partir de um sistema de cooperação, representado pelo trabalho comunitário nesses núcleos receptores. Tratase de uma pesquisa qualitativa explicativa, que utiliza entrevista com roteiro semiestruturado, além do recolhimento de informações em fontes bibliográficas. A pesquisa de campo foi realizada no mês de janeiro de 2010, quando, foram percorridos $215 \mathrm{~km}$ pela costa leste do estado do Ceará para a obtenção de registros e depoimentos de pessoas representativas das comunidades envolvidas. Em cada uma das comunidades, a 
permanência no território se deu em instalações comunitárias com hospedagem domiciliar, o que permitiu participar do cotidiano destas comunidades.

As comunidades visitadas foram: Alojamento Frei Humberto $\left(\mathrm{MST}^{1}\right)$, Associação Mulheres em Movimento, Batoque, Jenipapo-Kanindé, Prainha do Canto Verde, Ponta Grossa, Assentamento Coqueirinho e Tremembé. A análise de campo buscou estruturar-se com base nos objetivos específicos da pesquisa, em especial, sobre como foram estabelecidos os vínculos sociais entre os envolvidos nas atividades do turismo comunitário e sobre como ocorria a organização do trabalho comunitário para o estabelecimento de redes de cooperação.

\section{DAR, RECEBER E RETRIBUIR - REFLEXÕES SOBRE A DÁDIVA NA SOCIEDADE MODERNA}

As sociedades modernas vivem em torno da hegemonia do sistema econômico capitalista dirigido pelos interesses do mercado e o consumismo desenfreado. Esse modelo econômico tem sido discutido mundialmente, pois além de sacrificar bens naturais não renováveis e restringir os recursos em prol do crescimento econômico, cria novas tendências mercantis que entusiasmam a mecanização do pensamento humano e ajustam novas regras de vida e comportamento para a sociedade. Segundo Godbout (1998), para essa modalidade política e econômica atual, existe um paradigma sociológico que explica tal comportamento e busca refletir sobre as tendências desse mecanismo para os atores desse sistema, que muitas vezes têm suas necessidades transformadas e maquiadas por instituições e autoridades em função do crescimento comercial.

Esse paradigma é conhecido como o neoliberalismo. Nas ciências humanas, ele possui diversos nomes: teoria da escolha racional, racionalidade instrumental, individualismo metodológico, utilitarismo, homo œconomicus, teoria econômica neoclássica, entre outros. (GODBOUT, 1998, p. 39). Ainda segundo o autor, as diversas

\footnotetext{
${ }^{1}$ O Movimento Sem Terra - MST é um movimento de trabalhadores rurais que protagonizam a democratização da terra, por meio de lutas em prol da reforma agrária. O Movimento Sem Terra está organizado em 24 estados nas cinco regiões do país. No total, são cerca de 350 mil famílias que conquistaram a terra por meio da luta e da organização dos trabalhadores rurais.
} 
nomenclaturas atribuídas ao paradigma, podem classificar seus diferentes aspectos, porém existe um ponto em comum em todos eles que pode resumir sua essência: “procura explicar o sistema de produção e, sobretudo, de circulação das coisas e dos serviços na sociedade a partir das noções de interesse, de racionalidade, de utilidade” (GODBOUT, 1998, p. 39). Segundo o autor, esse sistema tende a guiar os atores do processo a partir de vontades criadas por meio de um ambiente imaginário em que as necessidades são criadas artificialmente para que o ciclo desejo-consumo seja abastecido periodicamente:

O membro da sociedade moderna se vê às voltas com um número impressionante de instâncias, de pessoas, de instituições, de autoridades, que tentam lhe dizer quais deviam ser seus valores, suas preferências, que tentam lhe dizer o que é bom para ele. Costumam ser instâncias externas à sua comunidade, que ele tende a considerar ilegítimas. (GODBOUT, 1998, p. 40).

Nesse caso, as relações são impessoais, não há envolvimento e não há promessa de uma relação em longo prazo. Para Godbout (1998, p. 40), as sociedades modernas encontram espontaneamente uma vantagem no sistema de mercado: a liberdade, traduzida pela facilidade de sair de uma relação que não se aprecia, e ir procurar outra, livre de regras e sem necessidade de explicações ou satisfações sociais. Segundo o autor, o modelo mercante visa à ausência de dívida.

Nesse modelo, cada troca é completa. Graças à lei da equivalência, predominante no sistema utilitarista, “cada relação é pontual, e não compromete o futuro. Não tem futuro e portanto, não nos insere num sistema de obrigações” (GODBOUT, 1998, p. 40). Nesse sentido, a liberdade moderna pode ser considerada essencialmente como a ausência da dívida. "O par constituído pelo individualismo e a economia neoclássica busca fundar a ética do comportamento do homem sem nenhuma dívida em relação a quem quer que seja” (SIMMEL apud GODBOUT, 1998, p. 41)². Assim, Berthoud (1994), classifica o mercado como um meio criado pela sociedade moderna, onde os indivíduos buscam sanar as dívidas pontualmente, sem que haja comprometimentos futuros. Para o autor, o mercado é "um laço social que visa escapar das obrigações normais inerentes aos laços sociais. É a essência da liberdade moderna. Nesse jogo infinito da circulação de equivalências, ser um indivíduo, equivale a não

\footnotetext{
${ }^{2}$ SIMMEL, G. Money in modern culture. Theory, Culture \& Society, Londres, 3. ed., p. 17-31. 1991.
} 
dever nada a ninguém" (BERTHOUD, 1994, p. 53). Nesse sentido, o homem da sociedade moderna torna-se seguro para concretizar sonhos e desejos, muitas vezes criados e manipulados pelo mercado, em um ambiente de liberdade de escolha e garantia de não atrelar pendências futuras a essas transações. Para Godbout (1998), esse modelo tende, a generalizar um valor, o valor de produto.

Se, graças à modernidade, libertamo-nos de nossos laços, por outro lado tornamo-nos cada vez mais dependentes de nossos bens, de nossos produtos e, principalmente, da necessidade de produzir cada vez mais. Em outras palavras, o que era meio (o produto) torna-se fim. Inverte-se a relação fimmeio. O que fora inicialmente definido como estando a serviço das preferências individuais - a produção - acaba sendo o valor supremo, a finalidade (GODBOUT, 1998, p. 41).

Em contraposição ao paradigma economicista e utilitarista, sociólogos e antropólogos desenvolveram estudos que criticam essa abordagem e apresentam outra forma de analisar o comportamento social, dessa vez partindo de um olhar coletivo e não mais restrito ao indivíduo. Esse novo paradigma preocupa-se em analisar as diferentes formas de holismo, termo que designa em sentido amplo, todas as teorias que falam da sociedade mais do que do indivíduo. Esse movimento recrimina o monopólio da economia neoclássica e se apresenta como uma alternativa ao paradigma utilitarista (GODBOUT, 1998). Ainda, segundo Godbout (1999, p. 37), a essência desse novo pensamento está em romper o isolamento do indivíduo e situá-lo no contexto de suas relações sociais. Etzioni (apud GODBOUT, 1998) ${ }^{3}$ denomina essa nova rede pensamento de "paradigma do eu e nós", que significa que cada indivíduo possui um sentimento de identidade compartilhada com os outros. Nesse novo paradigma, os atores sociais não agem somente em função de seus interesses, mas sim em função de normas e valores coletivos. Para Etzioni (1988, p. 41-43), os atos morais tendem a representar os ímpetos sociais sobre compromissos não deliberados:

\begin{abstract}
Atos morais refletem um imperativo, uma generalização, e uma simetria quando aplicados aos outros [...] são intrinsecamente motivados e não passíveis de uma análise meios-fins. [...] repudiam a racionalidade instrumental que inclui a consideração de custos e benefícios. [...] De fato, a "instantaneidade" de tais decisões é usada por várias pesquisas como uma indicação de que se trata de um compromisso não deliberado. (ETZIONI, 1988, p. 41).
\end{abstract}

\footnotetext{
${ }^{3}$ ETZIONI, A. The moral dimension: Toward a new economics. Nova York: The Free Press, 1988.
} 
Os dois paradigmas descritos representam que as relações sociais decorrem a partir da liberdade e da livre escolha, onde os indivíduos podem seguir guiados pelo modelo da racionalidade, ou por um comportamento determinado por normas, pela obediência a regras. Para Caillé (1998), nenhum dos dois grandes paradigmas apresentados podem elucidar questões relativas ao comportamento social. Por isso, ele propõe e instiga reflexões acerca da dádiva e sobre os estudos realizados inicialmente por Marcel Mauss, e que hoje são conduzidos por autores representantes do movimento "Mouvement Anti Utilitariste em Sciences Sociales (M.A.U.S.S.)" - Movimento Antiutilitarista em Ciências Sociais, entre os quais, Alain Caillé foi o precursor. Para Caillé (1998), a dádiva desafia os grandes paradigmas propostos e por isso merece destaque dentre as pesquisas sociológicas.

\begin{abstract}
Entende-se por dádiva tudo o que circula na sociedade que não está ligado nem ao mercado, nem ao Estado (redistribuição), nem à violência física. De modo mais positivo, é o que circula em prol do ou em nome do laço social. Não é um fenômeno irrelevante. Basta pensar no que circula entre amigos, entre vizinhos, entre parentes, sob a forma de presentes, de hospitalidade e de serviços. Na sociedade moderna, a dádiva circula também entre desconhecidos: doações de sangue, de órgãos, filantropia, doações humanitárias, benevolência, etc. (GODBOUT, 1998, p. 43).
\end{abstract}

A dádiva não corresponde ao modelo mercantil; uma de suas principais características consiste no fato de que os agentes sociais não estão condicionados à equivalência e a quitação das dívidas contraídas. O movimento da dádiva não é unilateral, embora a retribuição não seja o objetivo no sistema da dádiva, geralmente, ela acontece, e muitas vezes maior do que a dádiva inicial. Para Godbout (1998, p. 43): “[...] O mercado se baseia na liquidação da dívida. A dádiva baseia-se, ao contrário, na dívida. Isso pode ser observado tanto nos laços primários como nas relações de parentesco, na doação a um desconhecido, na doação de órgãos”. A dádiva não corresponde ainda ao paradigma holista, pois enquanto os agentes nesse sistema agem por obrigação às regras e normas, no sistema da dádiva, os atores valorizam o prazer envolvido na relação. Segundo Godbout:

Uma dádiva feita por obrigação, por obediência a uma norma, é considerada de qualidade inferior e por isso a moral do dever não se aplica à dádiva. [...] os membros de um sistema de dádiva possuem uma relação muito particular com as regras [...] Antes de mais nada, as regras devem estar implícitas. Por isso, é de muito mau gosto deixar o preço num presente, ou aludir a ele. (GODBOUT, 1998, p. 44). 
No sistema da dádiva - o doador, por muitas vezes chega a negar a importância da dádiva. Ao doar algo, é comum responder após o agradecimento, “de nada”, como forma de diminuir a obrigação de retribuir e tornar a retribuição incerta. Esse mecanismo torna o outro livre para dar por sua vez. Oportuniza-se assim ao receptor fazer uma verdadeira dádiva (GODBOUT, 1998).

\begin{abstract}
Constata-se, desse modo, que os atores da dádiva introduzem, deliberada e permanentemente, uma incerteza, uma indeterminação, um risco quanto à efetivação do contradom, de modo a se afastarem o máximo possível do contrato, do comprometimento contratual (mercantil ou social), e também da regra do dever; na verdade, de qualquer regra de tipo universal. Por quê? Porque estas últimas têm a propriedade de obrigar o outro independentemente de seus "sentimentos" em relação a mim, independentemente do elo que existe entre o outro e eu (GODBOUT, 1998, p. 44).
\end{abstract}

De acordo com Caillé (1998) o sistema da dádiva, representado pela tríplice obrigação - dar, receber e retribuir, é um modelo de ação social totalmente diferente e paradoxal, pois estabelece ao mesmo tempo, uma relação de "liberdade e obrigação" e de “interesse e desinteresse”. O ritual da dádiva não se resume em mero ritual, pelo contrário, em uma relação que envolve dádiva, há expressão obrigatória de sentimentos de generosidade, gratidão e espontaneidade (CAILLÉ, 1998). Em suma, as formas de liberdade e dívida descritas no sistema da dádiva são diferentes daquelas contraídas pelo sistema mercantil. Na dádiva, não há preocupação em relação à contração da dívida e não consiste na facilidade, para o ator, de sair da relação; “situa-se, ao contrário, dentro do laço social, e consiste em tornar o próprio laço mais livre, multiplicando os rituais que visam diminuir, para o outro, o peso da obrigação. A dádiva é um jogo entre liberdade e obrigação” (GODBOUT, 1998, p. 44). Assim, o modelo da dádiva não se liga, a nenhum dos dois paradigmas dominantes. A não equivalência, a espontaneidade, a dívida, o prazer do gesto e a liberdade se opõem às teorias de holismo e individualismo metodológicos. Para o autor, "[...] a verdadeira dádiva é um gesto socialmente espontâneo, um movimento impossível de captar em movimento, uma obrigação que o doador dá a si mesmo, mas uma obrigação interna, imanente”. (GODBOUT, 1998, p. 46). 


\section{UMA ECONOMIA DIFERENCIADA EM UMA SOCIEDADE DA DÁDIVA}

Para Donati (apud GODBOUT, 1998, p. 47) ${ }^{4}$ a dádiva seria uma experiência que permite pertencer a uma comunidade que não limita seus indivíduos, pelo contrário, tem por objetivo, expandir os pensamentos em uma voz comum. Para o autor, a dádiva está presente em uma comunidade de forma a fazê-la prosperar, contrariamente a uma visão individualista, a experiência da solidariedade comunitária não contradiz a identidade e pode, ao contrário, desenvolvê-la. Nesse sentido, Caillé (1998), descreve que a dádiva seria, uma experiência social fundamental, de experiência dos fundamentos da sociedade, daquilo que liga as pessoas a ela para além das regras cristalizadas e institucionalizadas como normas da justiça. A constituição do sistema da dádiva quando completo em um ciclo, pode ser denominado de "fato social total - uma experiência que concretiza a ligação entre indivíduo e sociedade, entre liberdade e obrigação. Uma experiência em que a sociedade é vivida como comunidade” (MAUSS apud CAILLÉ, 1998, p. 16) ${ }^{5}$. Nas sociedades e comunidades, o sistema do dom, representado pela tríplice-obrigação ocorre por diversos motivos: para que as pessoas estejam ligadas, para se conectarem à vida, para fazer circular as coisas num sistema vivo, para romper a solidão, sentir que não se está só e que se pertence a algo mais vasto, entre outros. Por isso, Caillé (1998, p. 21) explica, “a dádiva é o que circula a serviço do laço social, o que o faz aparecer, o que alimenta”. A dádiva é o sistema que propicia o vínculo pela comunicação, atua para romper o isolamento e para que as pessoas sintam sua própria identidade. Por isso é perceptível o sentimento de poder, de transformação, de abertura, de vitalidade que invade os doadores, que dizem que recebem mais do que dão. “A dádiva seria, então, um princípio consubstancial ao princípio vital, aos sistemas vivos” (CAILLÉ, 1998, p. 23). Nesse sentido, é possível observar algumas comunidades que interagem consciente ou espontaneamente por meio do sistema da dádiva. Essas comunidades, que serão apresentadas a seguir são reconhecidas por desenvolverem atividades cotidianas que utilizam o sistema do dom como canal principal para aproximar pessoas, firmar laços e constituir alianças. Nessas

\footnotetext{
${ }^{4}$ DONATI, P. Identity and solidarity in the complex of citizenship: the relational approach. International Sociology, v. 10, n. 3, p. 299-314, 1995.

${ }^{5}$ MAUSS, M. Ensaio sobre a dádiva: forma e razão da troca nas sociedades arcaicas. In: Sociologia e Antropologia. São Paulo: Edusp, v. 2, p. 37-184, 1974.
} 
comunidades, o turismo comunitário, observado como atividade complementar à economia tradicional, é responsável pela constituição de vínculos, formados a partir de atividades integradas de cooperação. As comunidades planejam, organizam e monitoram a atividade turística com vistas ao desenvolvimento social coletivo e compartilham dos benefícios gerados de forma equivalente a todos os envolvidos. Entre as principais atividades observadas do turismo comunitário, que podem ter características do sistema da dádiva, destacam-se: a construção de pousadas comunitárias em sistema de mutirão - ação que envolve toda a comunidade para a construção de hospedagem para visitantes. Durante a construção das pousadas, enquanto os homens trabalham na edificação da estrutura, as mulheres preparam o almoço comunitário, que propõe a reunião de todos os participantes em um momento de confraternização. Pode-se observar também que as manifestações artístico-culturais resguardadas e compartilhadas com os visitantes, tornam o vínculo comunitário ainda mais intenso à medida que nutre a valorização pela cultura tradicional caiçara. Destacase ainda, a participação comunitária integrada representada por associações de planejamento de atividades turísticas. As associações comunitárias têm por objetivo monitorar e avaliar a gestão da atividade nas comunidades, promovendo a discussão sobre a divisão equitativa dos dividendos e sobre a aplicação dos recursos excedentes em projetos de melhoria para as comunidades. As associações de moradores discutem ainda sobre a implementação de práticas sustentáveis, para minimização de impactos causados pelo turismo nos núcleos receptores. Muitas dessas ações foram estudadas, aprovadas em consenso comunitário e colocadas em prática, como por exemplo, as oficinas para turistas de "conscientização para a pesca da lagosta”, "reaproveitamento de alimentos”, “reciclagem de lixo e reuso da água”, além da implementação de trilhas ecológicas e passeios culturais, como produtos diferenciais da oferta turística comunitária. Envolvidas neste processo, essas comunidades passam a estabelecer vínculos solidários a partir da formação de redes de cooperação. Nesse sentido, observase a participação de indivíduos em uma economia diferenciada, que não segue os padrões economicistas e que será denominada nesse trabalho de economia da dádiva.

Em Ciências Sociais, a economia da dádiva ou economia do dom é uma forma de organização social na qual os membros fazem doações de bens e serviços, uns aos outros, sem que haja, expectativa de reciprocidade, como no sistema economicista. 
Todavia, a obrigação de reciprocidade existe, não necessariamente envolvendo as mesmas pessoas, mas como uma corrente contínua de doações. Pode ser caracterizada e comparada às economias primitivas, que são autosuficientes, pois utilizam o sistema de troca do excedente produzido, pelos poucos bens que não conseguem produzir. Essa economia pode coexistir, com as economias planificadas, ou de mercado. Segundo Mauss (1974, p. 54), dispor de um bem, seja ofertando-o ou destruindo-o, é a base para a formação de alianças e geração de respeito. Permeados sempre por significados simbólicos diversos, os contratos são feitos com base na oferta. Dispor de um objeto significa fazer um pacto. A economia do dom é uma forma de organização, não um tipo de contrato que se assina conscientemente. Segundo Mauss, "não se está falando em termos legais: estamos falando de homens e grupos de homens, porque são eles, é a sociedade, são os sentimentos humanos que se transformam em ação” (MAUSS, 1974, p. 47).

Nas comunidades da costa leste do Estado do Ceará, o turismo comunitário revela-se como atividade que concentra o saber humano como foco das ações. O trabalho é realizado com ênfase no bem-estar coletivo, organizado por uma gestão que evidencia as habilidades tradicionais e as transforma em ferramentas para o desenvolvimento de uma economia diferenciada, orientada pela troca de saberes, experiências e serviços para a dinamização do turismo.

\section{REDES DE COOPERAÇÃO COMUNITÁRIA E O TRABALHO ASSOCIADO}

Para Caillé (2002, p. 16), a rede “é o conjunto de pessoas com as quais o ato de manter relações de amizade ou de camaradagem, permite conservar e esperar confiança e fidelidade”. Segundo o autor, é importante reconhecer que essas redes, tradicionais ou modernas, são alianças generalizadas criadas na aposta na dádiva e na confiança.

Círculo ou rede, dá no mesmo. Sem saber — já que os sociólogos americanos ignoram completamente Mauss -, Granovetter centra sua reflexão a respeito das redes exatamente naquilo que Mauss descobrira em sua busca da dádiva através da infinita variedade de culturas: fidelidade e confiança. A única coisa que falta a priori nessas análises é reconhecer que essa aliança generalizada que constitui as redes, atualmente como nas sociedades arcaicas, só se cria a partir da aposta da dádiva e da confiança. E constatar que o vocabulário da fidelidade e da confiança é indissociável do da dádiva (Servet, 
1994), já que é a palavra dada, mais do que o juramento e antes dele (Verdier, 1991). A referência à dádiva, em razão de sua natureza simbólica, abre imediatamente para uma dimensão que é irredutível às redes concretas e empiricamente determinadas. (CAILLÉ, 2002, p. 16).

Isto significa dizer que a obrigação social que une os membros de uma rede não tem apenas caráter moral, mas igualmente político, dado pelo interesse dos membros na aliança. A formação de redes de cooperação resulta de uma busca progressiva de um pensamento sociológico antiutilitarista e humanizante que, ao longo do século XX, valoriza a força da associação como recurso explicativo poderoso dos movimentos coletivos e espontâneos (MARTINS, 2002, p. 9). Para o autor, a rede social responde a uma exigência a partir de demandas práticas, representadas por meio de novas metodologias de intervenção social, ou novas formas de participação e de mobilizações coletivas. A teoria da rede social revela a preocupação em explicar o fato social não a partir da liberdade individual, mas de uma formação coletiva que se impõe às vontades individuais.

Para Mauss (apud, CAILLÉ, 1998, p. 45) ${ }^{6}$, o fato social, para aparecer como "fenômeno total”, exige que a observação seja centrada sobre o conjunto de bens materiais e simbólicos que circulam no interior da sociedade, determinando que os lugares próprios e singulares de cada membro sejam compreendidos pelo ângulo da totalidade. Assim, Martins (2000, p. 12), conclui que a introdução da noção de rede nos estudos sociológicos constitui um objeto importante para se avançar na discussão sobre as mobilizações sociais a favor das redes de cidadania. O sociólogo italiano Alberto Melucci (apud MARTINS, 2000, p. 14) ${ }^{7}$ afirma que os movimentos são naturalmente sugeridos por uma estratégia de redes - pequenos grupos imersos na vida cotidiana, na qual os membros, mediante suas experiências e inovações culturais, contribuem para o seu desenvolvimento. Martins e Fontes (2004, p. 14), também colaboram com reflexões sobre o assunto e definem o movimento das redes como sendo "redes de redes" - um sistema associativo que produz e divulga a mobilização dos indivíduos para associação em novas redes. Para os autores, o conceito de rede permite compreender que cada ator social tende a se inscrever em diferentes círculos de troca, em um movimento

\footnotetext{
${ }^{6}$ MAUSS, M. Ensaio sobre a dádiva: forma e razão da troca nas sociedades arcaicas. In: Sociologia e Antropologia. São Paulo: Edusp, v. 2, p. 37-184, 1974.

${ }^{7}$ MELUCCI, A. Um objetivo para os movimentos sociais? Lua nova, n. 17. São Paulo: CEDEC, n. 17, jun. 1989.
} 
permanente em que as redes de mediação tanto geram novas redes como renovam as antigas.

A noção de rede coloca a ênfase nas relações entre diversidades que se integram em laços de sinergia coletiva, que facilitam a transformação de cada parte pela sua relação com as demais. (MANCE, 1999, p. 46). A Rede de Colaboração Solidária integra grupos de consumidores, de produtores e de prestadores de serviço em uma mesma organização, onde todos se propõem a praticar o consumo solidário, por meio da aquisição de produtos e serviços da própria Rede, sendo que o excedente obtido é reinvestido, o que garante a sustentabilidade das ações e o consumo de todos. Mance ainda afirma que:

\footnotetext{
Quatro são os critérios básicos de participação nessas redes: a) que nos empreendimentos não haja qualquer tipo de exploração do trabalho, opressão política ou dominação cultural; b) busque-se preservar o equilíbrio ecológico dos ecossistemas (respeitando-se todavia a transição de empreendimentos que ainda não sejam ecologicamente sustentáveis); c) compartilhar significativas parcelas do excedente para a expansão da própria rede; d) autodeterminação dos fins e autogestão dos meios, em espírito de cooperação e colaboração (MANCE, 1999, p. 46).
}

Quando redes locais deste tipo são organizadas, elas operam no sentido de atender demandas imediatas da população por trabalho, melhoria no consumo, educação, reafirmação da dignidade humana das pessoas e do seu direito ao bem viver, ao mesmo tempo em que combatem a exploração e dominação responsáveis pela pobreza e exclusão. As redes de colaboração solidária, portanto: a) permitem aglutinar diversos atores sociais em um movimento orgânico com forte potencial transformador; b) atendem demandas imediatas desses atores por emprego de sua força de trabalho; c) negam estruturas capitalistas de exploração do trabalho, de expropriação no consumo e de dominação política e cultural; e d) passam a implementar uma nova forma póscapitalista de produzir e consumir, de organizar a vida coletiva afirmando o direito à diferença, promovendo solidariamente (MANCE, 1999, p. 52).

Para Caillé (1998), as análises em termos de redes se inscrevem no quadro da reflexão aberta por Marcel Mauss. Segundo o autor, os dois grandes paradigmas sociais representados pelo holismo e individualismo, têm em comum o fato de pensarem a sociedade segundo um eixo vertical: 
Raciocinar em termos do interacionismo da dádiva, de pensamento do político, é, ao contrário, adotar um ponto de vista radicalmente imanente, horizontalista, e mostrar que é do mesmo movimento que se produzem ou se reproduzem os termos opostos, a base e o topo. Nesse sentido, entende-se que não há nem indivíduo nem sociedade - nem natureza nem sociedade, mas a (inter)ação dos homens concretos. (CAILLÉ, 1998, p. 16).

O autor também menciona acreditar que a sociedade vive em um momento de pressões para reforma do sistema político em geral e a discussão sobre rede, parece estratégica para auxiliar teórica e politicamente as mobilizações sociais, permitindo que as organizações não-governamentais e associações locais possam administrar os problemas que atingem a sociedade (CAILLÉ, 1998).

Partindo das reflexões sugeridas por Mauss e Caillé acerca do interacionismo em redes para a mobilização de sistemas políticos, econômicos e sociais, Coraggio (apud Leite, 2009) ${ }^{8}$ desenvolveu uma reflexão teórica, com base nos princípios da economia solidária, mas a partir do que ele denomina “economia do trabalho”. Esta é entendida pelo autor como uma economia social que vai além dos interesses individuais e que busca, primordialmente, a criação de bens coletivos. Este tipo de economia, baseada nas unidades domésticas, contemplaria um conjunto de atividades, entre as quais as cooperativas e outras formas de ações econômicas, apareceriam juntamente com o trabalho por conta própria e as atividades de produção de bens e serviços que são consumidos pelas unidades domésticas sem passar pelo mercado. Tais atividades incluem o trabalho de limpeza, da cozinha, de tomar conta das crianças, na horta, do conserto e confecção de roupas, de construção de móveis, da própria casa etc.

Para o autor, o conjunto da população trabalhadora não consegue ser inserido em empreendimentos do sistema capitalista atual. Ainda assim, a limitação das políticas públicas em face do desemprego e da precarização do trabalho estariam levando a população excluída a buscar formas de subsistência na economia doméstica, cuja lógica não é da reprodução do capital, mas da reprodução ampliada da vida. Nesse sentido, o autor considera que é a partir da economia do trabalho, que se poderia apoiar a empresa social: “empreendimentos que não só produzem mercadorias, mas que 'produzem sociedade”. Tal tipo de empreendimento 'investe num único capital que possui: 'as pessoas' e isto começa por dar créditos a elas, no sentido da reprodução ampliada da

${ }^{8}$ CORAGGIO, J. Da economia dos setores populares à economia do trabalho. In: KRAYCHETE, G.; LARA, F.; COSTA, B. (Orgs.). Economia dos setores populares: entre a realidade e a utopia. Petrópolis, RJ, Vozes. 2000. 
vida, que para o autor significa, a melhoria da qualidade de vida com base no desenvolvimento das capacidades e das oportunidades sociais das pessoas (CORAGGIO, 2000, p. 98).

Coraggio (2003) admite a possibilidade do desenvolvimento de relações de cumplicidade e ao mesmo tempo de fortalecimento de laços sociais entre os envolvidos na economia do trabalho, o autor acredita na possibilidade de uma economia alternativa:

[...] que se desenvolveria a partir da economia dos setores populares, fortalecendo suas vinculações e capacidades, potencializando seus recursos, sua produtividade, sua qualidade, assumindo novas tarefas, incorporando e autogerindo os recursos de políticas sociais de modo a fortalecer os laços sociais entre seus membros, seus segmentos, suas micro-regiões; uma economia que estruturalmente distribua com mais igualdade, que supere essas tendências à exploração ou à violência, que seja um setor da sociedade mais harmônico e integrado com outros valores de solidariedade, com maiores recursos voltados para a cooperação (CORAGGIO, 2003, p. 123).

Embora o autor não considere que a economia do trabalho seja inexorável, ele a vê como uma promessa que pode satisfazer diretamente parte das necessidades das maiorias locais e competir exitosamente no mercado nacional ou global, "gerando ocupações mercantis e os ingressos monetários necessários para sustentar-se e ampliarse sobre suas próprias bases de interdependência" (CORAGGIO, 2000, p. 116). Esse sistema não se constituirá, contudo, naturalmente, mas "requer que se invistam energias importantes no desenvolvimento, consolidação e alimentação de redes que articulem, comuniquem e dinamizem a multiplicidade de empreendimentos e microredes populares" (CORAGGIO, 2000, p. 116).

O turismo comunitário nas comunidades estudadas apresentou-se como atividade que privilegia atividades domésticas de produção, como o cultivo de hortas e pomares, a criação de animais, a prestação gratuita de serviços domésticos, (limpeza das casas e pousadas comunitárias), a confecção de artesanatos para utilização em diversos fins, entre outros. Todas as atividades são desenvolvidas tendo como princípio o bemestar coletivo e a troca de saberes por meio da cooperação do trabalho, por isso, possibilitam a formação de vínculos de proximidade e cumplicidade entre os moradores da comunidade. 


\section{DÁDIVA E TURISMO COMUNITÁRIO: VÍNCULOS SOCIAIS E COLABORAÇÃO SOLIDÁRIA NO CEARÁ}

A pesquisa buscou apresentar um diálogo sobre a constituição de vínculos sociais estabelecidos espontaneamente a partir de um sistema de cooperação, representado pelo trabalho comunitário em pequenos núcleos receptores na costa leste do Estado do Ceará. Tratou-se de uma pesquisa qualitativa explicativa, que utilizou entrevista com roteiro semi-estruturado, além do recolhimento de informações em fontes bibliográficas. Foram entrevistadas sete pessoas, entre líderes comunitários e representantes de organizações sociais envolvidas com a gestão do turismo comunitário. O critério de seleção dos entrevistados baseou-se na participação e representatividade na gestão do turismo de base local cearense e no sistema da economia solidária; no envolvimento com projetos e ações que promovam o turismo sustentável na costa cearense; na participação e representatividade em setores governamentais que buscam fomentar e dar suporte à atividade turística no Ceará; na participação em projetos sociais ligados ao turismo cearense, desenvolvidos por ONGs (Organizações não governamentais) com o objetivo de preservar e disseminar a educação ambiental para turistas e comunidade local.

A pesquisa de campo foi realizada em janeiro de 2010, quando, foram percorridos $215 \mathrm{~km}$ pela costa leste do estado do Ceará para a obtenção de registros e depoimentos. Em cada uma das comunidades, a permanência no território se deu em instalações comunitárias com hospedagem domiciliar, o que permitiu participar do cotidiano destas comunidades. As comunidades visitadas foram: Alojamento Frei Humberto, Associação Mulheres em Movimento, Batoque, Jenipapo-Kanindé, Prainha do Canto Verde, Ponta Grossa, Assentamento Coqueirinho e Tremembé.

Essas comunidades possuiam infra-estrutura precária para o turismo, porém se esforçavam para estruturar estratégias e parcerias que pudessem permitir o avanço em pontos importantes para o desenvolvimento do turismo comunitário. Com o auxílio de organizações não governamentais, observou-se nessas comunidades, a implantação de processos de formação em turismo, na perspectiva de empoderamento das lideranças comunitárias e de desenvolvimento de habilidades e competências voltadas para o desenvolvimento do turismo comunitário. Além disso, observou-se o planejamento 
estratégico para a melhoria das infra-estruturas turísticas e das infra-estruturas básicas. Em parceria com o Instituto Terramar ${ }^{9}$, as comunidades passaram a trabalhar na construção de estratégias de marketing e promoção dos produtos e serviços turísticos comunitários, divulgar os produtos e serviços com os organizadores e operadores de viagens e a comercializar o turismo comunitário solidário.

Dentre os principais produtos e serviços turistícos oferecidos pelas comunidades identificou-se: serviços de alimentação; hospedagem; traslado das principais rodovias até as comunidades; monitoramento e guia em trilhas ecológicas; venda de produtos artesanais tradicionais; oficinas de sustentabilidade sócio-ambiental; apresentações artísticas tradicionais; vivências tradicionais (participação em atividades cotidianas das comunidades caiçaras com o objetivo de experienciar as suas práticas, como por exemplo, participar da atividade de pesca, agricultura, confecção artesanal, preparação de gastronomia caiçara, entre outros).

Como estratégia futura para o desenvolvimento do turismo comunitário, essas comunidades, manifestaram pretender articular-se com outras redes de turismo comunitário no Brasil e no exterior que estão construindo o turismo comunitário solidário. E que pretendiam ainda, promover formas de oferta turística locais para garantir às populações tradicionais a permanência em seus territórios (há décadas existe um acentuado processo de expulsão das populações costeiras) e possibilitar a continuidade das atividades econômicas tradicionais, em particular a pesca e a agricultura.

O estudo teve como objetivo central verificar a constituição de vínculos sociais estabelecidos a partir de um sistema de cooperação integrado, realizado nas comunidades localizadas na costa leste do Estado do Ceará. Trabalhou-se com foco na problemática sobre como estavam estabelecidas as redes de turismo comunitário solidário e como se dava a formação de alianças entre os envolvidos nas atividades comunitárias na costa cearense. Algumas hipóteses foram levantadas com base em estudos preliminares, como por exemplo: se as atividades relacionadas ao turismo de base comunitária favoreciam a formação de vínculos comunitários a partir da troca de

\footnotetext{
${ }^{9}$ O Instituto Terramar é uma organização não-governamental, sem fins lucrativos, do campo popular democrático que atua na Zona Costeira do Ceará, visando o desenvolvimento humano com justiça socioambiental, cidadania, participação política, autonomia dos grupos organizados e fortalecimento da identidade cultural dos Povos do Mar do Ceará.
} 
experiências e saberes tradicionais; que o trabalho comunitário estava organizado em projetos coletivos e baseava-se na ética e na solidariedade para estabelecer as relações comerciais; que a gestão fundamentava-se na construção de uma relação entre sociedade, cultura e natureza em prol da sustentabilidade sócio-ambiental. Trata-se de uma pesquisa qualitativa explicativa, a qual focou esses pequenos núcleos receptores, como estudo de caso. Os dados coletados foram analisados utilizando o método de análise de conteúdo e por isso, foram agrupados em categorias temáticas, a saber: $\mathbf{1}^{\mathrm{a}}$ Representação de vínculos por colaboração solidária e $2^{\mathrm{a}}$ - Organização social do trabalho comunitário. A pesquisa foi realizada após alguns meses de negociações com os organizadores, que deram apoio e autorização prévia. Para análise da pesquisa, foram realizadas entrevistas formais (utilizando instrumento de pesquisa semi-estruturado) e informais, além de documentos analisados em museus, centros culturais e bibliotecas.

\section{$1^{\mathrm{a}}$ - Representação de vínculos por colaboração solidária}

Observou-se que as comunidades estudadas, articulavam-se prioritariamente a partir de um sistema de cooperação informal às regras do trabalho oficial. Nessas comunidades os laços sociais estavam formados a partir da cooperação e reciprocidade, que se tornavam os principais meios de proposta de sociabilidade. As famílias envolvidas na rede de trabalho dispunham gentilmente suas habilidades aos demais, propondo a criação de uma rede de trocas. Na maioria das vezes, para esses gestos, havia retribuição, por isso, implicitamente e de forma sutil, “a obrigação” de dar em retribuição era destacada pela gratuidade e pela liberdade. Para todas as trocas simbólicas realizadas nessas comunidades verificou-se existir a sensação de espontaneidade e generosidade. Notou-se que todos os envolvidos nesse sistema, preocupavam-se em retribuir a dádiva recebida de forma criativa e cuidadosa, para que a retribuição fosse envolvida pelo sentimento de gratidão absoluta, afirmando a perenidade da relação. Muitas vezes o agrado retribuído podia ser apenas um gesto de atenção, ao ouvir uma história a beira do rio, ou a simples companhia em uma noite de calor - nessas comunidades, observou-se que os pequenos gestos em retribuição às dádivas recebidas, eram fortemente percebidos, registrados e considerados pelos receptores. 
Observou-se ainda, que as comunidades cearenses procuravam evitar a circulação monetária. Os serviços prestados nas comunidades eram realizados de acordo com as aptidões individuais, em um movimento que buscava trocar saberes e valorizar cada uma das experiências do grupo. Nesse sentido, as pequenas comunidades possuíam integrantes com mais habilidades em determinadas atividades, sendo esse, o responsável por repassar suas aptidões à frente e divulgar ao grupo seus saberes especiais. Esses ensinamentos, muitas vezes tornavam-se serviços prestados, que eram retribuídos das mais diversas maneiras. Existia assim, a afirmação de uma convenção de gratuidade para essas ações, que seriam recompensadas com outros gestos. Para essas relações, a simples troca mercantil não poderia preencher a quantidade nem a qualidade do vínculo estabelecido. Esses vínculos faziam parte de uma cadeia ininterrupta, e as dádivas concedidas, muitas vezes não eram consideradas como dádivas pelos seus doadores. Muitos afirmaram que não notaram sua atitude de retribuição ou que não perceberam em si, um gesto acolhedor ou confortante. Percebeu-se assim, que o dom circulante nessas comunidades, estava recoberto de gratidão autêntica, onde a dádiva atuava por si só, estruturando um sistema espontâneo de cooperação, representado por trocas simbólicas.

Assim, o dom tornava-se uma sequência arbitrariamente destacada por propostas de vínculos que estabeleciam boas relações. O que circulava entre os moradores das comunidades estudadas, estava a serviço do laço. Ao contrário da troca mercantil, a sequência não era fechada, e os papéis não eram finitos. De certa maneira, nesse sistema de laços sociais, notou-se cotidianamente que a equivalência do mercado tendia a ser substituída por uma "nova economia", que valorizava o trabalho humano e que propunha a aliança social e a cooperação integrada como reparadoras dos problemas ocasionados pelo utilitarismo. Da mesma forma, percebeu-se que as dívidas assumidas pelo vínculo, eram aceitas de forma aberta e sincera, indicando que para cada dádiva recebida, existia um envolvimento em um processo prazeroso que invadia a promessa de retribuição.

A sequência do dom, representada pelas comunidades estudadas não comprometeu apenas os dois indivíduos envolvidos nesse sistema, mas também as suas famílias. As representações de sentimentos de amizade e fraternidade estavam presentes nas atividades cotidianas das comunidades. Acredita-se que nem mesmo essas 
comunidades soubessem a proporção dos vínculos criados a partir do sistema de cooperação solidária estabelecido, afinal, são muitas as comunidades que podem ser consideradas beneficiadas com os enlaces da cooperação mútua, propiciando a troca de experiências e a valorização do trabalho tradicional. É possível que os laços estabelecidos tenham tomado proporções tão maiores do que aquelas que a população local pudesse reconhecer. Isso porque, os indivíduos estavam inseridos numa rede de alianças que não se isolavam, ao contrário do que se observa numa transação mercantil, todas as ações vigoradas nesse processo eram seladoras de novas comunhões, que por sua vez, foram responsáveis por gerar novas redes colaborativas e assim por diante.

\section{$2^{\text {a }}$ - Organização Social do Trabalho Comunitário}

Nas comunidades estudadas, os grupos eram organizados em projetos coletivos de base familiar. Essas comunidades eram orientadas por um trabalho que primava pela troca de saberes e experiências mútuos e as atividades turísticas eram realizadas por meio de redes colaborativas, estabelecidas a partir de vínculos sociais criados espontaneamente como propostas para uma gestão solidária. Nessas comunidades, notou-se que o valor central das atividades estava relacionado ao trabalho, ao saber e a criatividade humanos e não o capital, em função disso, para cada meta estabelecida e para cada atividade cumprida, existia o reconhecimento ao grupo o que elevava a autoestima, valorizava as competências e motivava o empenho ao trabalho.

Para essas comunidades, o turismo comunitário fundamentou-se na diversidade de culturas e tradições, promovendo a valorização da produção, da cultura e das identidades locais e por isso, os pescadores reconheceram as práticas tradicionais como a mais importante das atividades econômicas fazendo com que as atividades relacionadas ao turismo comunitário, fossem integradas à dinâmica produtiva local, sem substituir as atividades tradicionais existentes.

Nas comunidades estudadas, cada participante estava consciente de fazer parte de um sistema orgânico e contribuir para o progresso próprio e do conjunto, valorizando as vantagens cooperativas e a eficiência sistêmica.

Nas comunidades estudadas, notou-se que a organização para o trabalho comunitário ocorreu em uma perspectiva horizontalizada. Isso quer dizer que não existia 
hierarquia absoluta entre os envolvidos nas atividades laborais - todos eram sócios. Todos os envolvidos na cadeia de produção do turismo valorizaram o saber humano e evidenciaram ao grupo as habilidades individuais, dessa forma, a comunidade não atuava como coadjuvante nos processos de planejamento e gestão do turismo, pelo contrário, participavam diretamente na articulação, coordenação e deliberação de projetos, como agentes econômicos, institucionais e sociais. Era também de competência do conselho comunitário, ponderar e decidir sobre a partilha e usos dos recursos excedentes, o que permitia que se fizessem investimentos concretos e de acordo com cada uma das realidades nas condições gerais de vida de todos. Observou-se também que a cooperação solidária nas comunidades promoveu o comércio a preços justos, de forma a favorecer a todos os envolvidos.

Em muitos casos analisou-se a formação de empreendimentos solidários que valorizavam o emprego da mão-de-obra do trabalhador tradicional, valorizando suas experiências e aptidões, em destaque ao trabalho que respeita a natureza e revela a cultura regional. Observou-se que o trabalho incorporado no processo produtivo dos empreendimentos solidários, não se revestiu das 'mesmas' propriedades da mercadoria do sistema de produção capitalista. Para esse modelo de trabalho e empreendimento solidário havia um diferencial: a cooperação e a solidariedade - responsáveis por favorecer a articulação e a agregação de interesses em âmbito mais amplo. Verificou-se que o modo como se organizou o trabalho comunitário solidário, trouxe uma série de satisfações adicionais, além da renda. A vivência do trabalho tornou-se edificante, como oportunidade de enriquecimento humano. Como se o lado gratificante e lúdico do trabalho neutralizasse sua face penosa, dotando a atividade produtiva de um novo sentido: colocar em prática os princípios de eqüidade, justiça e democracia e demonstrar a importância do trabalhador. As trocas sociais nesse caso eram estabelecidas essencialmente pela toca de experiências e saberes entre os envolvidos nas atividades do turismo comunitário.

\section{CONSIDERAÇÕES FINAIS}

A falta de alternativas de emprego e os baixos salários são índices incidentes para as famílias tradicionais residentes na costa cearense. Nesse território é possível 
encontrar crianças e adolescentes que são rendidos ao subemprego e até mesmo à prostituição, em função de um mercado segregador, responsável pela exclusão social. Tendo esse cenário como base, muitas famílias cearenses resolveram unir forças e construir uma estratégia alternativa que pudesse abrir espaço para os desfavorecidos, em busca do desenvolvimento local. Essas famílias propuseram então, uma economia centrada no trabalho, uma "outra economia" que, sem a pretensão imediata de substituir a economia centrada no capital, fosse capaz, no entanto, de disputar com ela. Nesse sentido, os núcleos familiares organizaram-se em um sistema integrado de cooperação que buscava trocar experiências e saberes, em prol do bem coletivo. Nessa região, a atividade turística passou a ser gerida pela comunidade, onde os ganhos econômicos são rateados por todos. Os grupos são organizados em projetos de base familiar e o turismo comunitário é idealizado partindo da ética e da solidariedade para estabelecer relações comerciais e de intercâmbio entre a comunidade e visitantes. As atividades turísticas são realizadas por meio de redes colaborativas estabelecidas a partir de vínculos sociais espontâneos como proposta para uma gestão solidária.

Por meio do sistema solidário de produção, foi possível observar o aparecimento de vínculos sociais estabelecidos entre os envolvidos, que direta ou indiretamente se organizaram nos moldes da economia solidária, sistema que supõe a relação de intercâmbio respeitoso entre o turista, a comunidade local e a natureza. O que circulava entre os moradores, estava a serviço do laço, da compreensão e do auxílio mútuo. Em contraposição à troca mercantil, nesse sistema de alianças, notou-se que a garantia de inclusão social era o eixo de todo o processo. Da mesma forma, em que as dívidas assumidas pelo vínculo, eram aceitas, existia uma promessa implícita de retribuição. As representações de amizade e fraternidade se fizeram presentes em atividades profissionais e a cada movimento de troca e aprendizado era possível perceber a intensificação desses sentimentos. São muitas as comunidades que podem ser consideradas beneficiadas com o sistema de cooperação implantado, que prima por valorizar o trabalho tradicional. É possível que os laços estabelecidos entre os indivíduos, por meio do trabalho comunitário, tenham tomado proporções maiores do que a população pudesse reconhecer, o que comprovou que muitos dos atores do processo desenvolviam ações solidárias de forma espontânea, sem alimentar esperança pelo retorno imediato. Ao aderir a essa prática, na qual predomina a atitude ética e 
solidária entre as populações locais e os visitantes, os indivíduos partilham uma nova forma de turismo, e contribui com a valorização das identidades locais e da produção cultural.

Conclui-se que a alternativa encontrada pelas comunidades tradicionais cearenses para a inclusão social, por meio do trabalho comunitário, beneficiou significativamente a todos os envolvidos, garantindo o fortalecimento dos laços sociais comunitários.

\section{REFERÊNCIAS}

BERTHOUD, G. L'économie: un ordre généralisé? Les ambitions d'un prix Nobel. In: La Revue du MAUSS, M. (Ed.). Pour une autre économie. Paris: MAUSS/Éditions La Découverte, v. 3, p. 42-59, 1994.

CAILLÉ, A. Antropologia do Dom: o terceiro paradigma. Petrópolis, Vozes, 2002.

. Nem holismo nem individualismo metodológico: Marcel Mauss e o paradigma da dádiva. In: Revista Brasileira de Ciências Sociais, São Paulo, v. 13, n. 8, p. 5-38, out. 1998.

CORAGGIO, J. L. Da economia dos setores populares à economia do trabalho. In: KRAYCHETE, G.; LARA, F.; COSTA, B. (Orgs.). Economia dos setores populares: entre a realidade e a utopia. Petrópolis, RJ: Vozes, 2000.

Política social y economía del trabajo. Zinacantepec, Estado de México, El Colegio Mexiquense, 2003.

ETZIONI, A. The moral dimension. Toward a new economics. Nova York: The Free Press, 1988.

GODBOUT, J. T. Introdução à dádiva. Revista Brasileira de Ciências Sociais, São Paulo, v.13, n. 38, p. 39-52, out. 1998.

O espírito da dádiva. Rio de Janeiro: Editora FGV, 1999.

LEITE, M. de P. A economia solidária e o trabalho associativo: teorias e realidades. Revista Brasileira de Ciências Sociais. [online]. v. 24, n. 69, p. 31-51, 2009. Disponível em: <http://www.scielo.br/scielo.php?script=sci_arttext\&pid=S010269092009000100003\&lng=en\&nrm=iso>. Acesso em: 10/09/2010.

MANCE, E. A. A revolução das redes: a colaboração solidária como uma alternativa pós-capitalista à globalização atual. Petrópolis: Vozes, 1999. 
MARTINS, P. H. Sociologia, intervenção e ação social. In: Estudos de sociologia: Revista do Programa de Pós-Graduação em Sociologia da UFPE, Recife, v. 5, n. 2, p. 15-28, 2000.

A dádiva entre os modernos: discussão sobre os fundamentos e as regras do social, Petrópolis, Vozes, 2002.

MARTINS, P. H.; FONTES, B. Redes sociais e saúde: novas possibilidades teóricas. Recife: Editora Universitária da UFPE, 2004, 159 p.

MAUSS, M. Ensaio sobre a dádiva: forma e razão da troca nas sociedades arcaicas. In: Sociologia e Antropologia. São Paulo: EPU; Edusp, 1974.

Recebido em: 07/08/2010.

Aprovado em: 06/09/2010. 